\title{
Advancements in shotcrete technology
}

\author{
G. Bernardo, A. Guida \& I. Mecca \\ Department of European and Mediterranean Cultures, \\ Basilicata University, Matera, Italy
}

\begin{abstract}
Shotcrete is a cement-based mixture pneumatically projected at high velocity onto a receiving surface. The material component of shotcrete is essentially concrete or sometimes mortar, but the process of shotcrete application is unique. This process allows a good compaction of concrete to be obtained without vibration. Compared to cast-in-place concrete, other important advantages of the shotcrete process are related to the reduction of the amount and time for formwork installation, removal, and associated labor costs, the very flexible logistics, very good working safety and good environmental conditions. Nowadays, because of the significant advances that occurred mainly in the last few decades, shotcrete can be considered a proper repair material particularly suitable in different situations such as where formwork is not practical or can be reduced or eliminated, where access to the work area is difficult, where thin layers and/or variable thickness is required and where normal casting techniques cannot be employed. This paper describes the two different application techniques of shotcrete, namely the dry-mix process and the wet-mix process, and discusses their respective advantages and disadvantages. The drawbacks of conventional shotcrete (only based on cement and aggregate mixtures) are reviewed and high performance shotcrete are presented. These novel shotcrete materials are produced through the addition of new generations of chemical admixtures, supplementary cementitious materials and reinforcement fibres. Cases histories of a successful use of the shotcrete process in the rehabilitations of architecturally important historic buildings are described.

Keywords: shotcrete, dry-mix process, wet-mix process, high performance shotcrete, rehabilitations, repairs, heritage building.
\end{abstract}




\section{Introduction}

Shotcrete, also termed as sprayed concrete, refers to a cement-based mixture that is proiected pneumatically at high velocity onto a target surface [1,2]. The material component of shotcrete is essentially concrete or sometimes mortar, but the technology of shotcrete is unique. It involves pneumatic projection of the concrete materials at high velocity so that compaction is achieved on the receiving surface [1-3].

Compared to cast-in-place concrete, the shotcrete technology offers different and significant advantages [4]. Shotcrete allows to obtain a good compaction without the concrete vibration and typically reduces the amount and time for formwork installation and removal. For remedial work and soil or rock stabilization when shooting against existing surfaces, the use of formwork can often be eliminated entirely. For structural shotcrete, single-sided formwork can be used to provide a receiving surface. The elimination of concrete vibration costs and the reduction or elimination of formwork reduce materials costs, shorten the construction schedule, and save labor costs. Other important advantages of shotcrete technology are related to the very flexible logistics and very good working safety and good environmental conditions.

Equipment for pneumatically applying a fine aggregate cement mixture (named as gunite) was developed in the early 20th Century in the United States [3]. From the first cement gun to the robotic spray arms now used all over the world, many advancements have been occurred in the equipment, in the specialized techniques required for pneumatically application and in materials technology $[3,4]$.

Shotcrete has traditionally been used in mining and tunnelling for the temporary constructions to ensure the workers safety. Because of the above mentioned technological advancements, shotcrete has gradually built up its reputation as a viable construction materials both in the field of new construction and in rehabilitations and repairs [3,4]. In the structural shotcrete reinforcing bars and wire fabric (uncoated or galvanized) can be used as reinforcement as in conventional concrete [5]. Properly applied shotcrete is nowadays a proven and durable construction material characterized by high strength, low absorption, good resistance to weathering and resistance to some forms of chemical attack. Many of the physical properties of shotcrete are comparable or superior to those of conventional concrete or mortar having the same composition.

In the architectural design the use of shotcrete overcomes the drawbacks of conventional concrete and virtually all structural elements, even complex shapes can be formed [4].

In the rehabilitations and repairs shotcrete is particularly advantageous in situations when formwork is cost prohibitive or impractical and where forms can be reduced or eliminated, access to the work area is difficult, thin layers or variable thicknesses are required or normal casting techniques cannot be employed. Moreover, the excellent bonding of shotcrete to surface of other damaged materials such as aging concrete, masonry surface, wood, steel structure is another useful property to perform effective and durable remedial work. The force of the impact of this pneumatically propelled material on the surface causes compaction 
of the shotcrete paste matrix into the fine surface irregularities and results in good adhesion to the surface. Within limits, the material is capable of supporting itself in vertical or overhead applications.

The present paper describes the two techniques of shotcrete application and their related advantages and disadvantages. It also presents the most recent advancements in the materials technology through which it is nowadays possible to overcome the drawbacks of conventional shotcrete based on only cement and aggregate mixtures and to use in rehabilitations and repairs high performance shotcrete, including new generations of chemical admixtures, supplementary cementitious materials, reinforcement fibres and polymer modifiers.

\section{Shotcrete processes}

Shotcrete can be applied by two distinct application techniques: the dry-mix process and the wet-mix process [1-3].

In the dry-mix process a mixture of cement and aggregate is batched and mixed without added water. The mixture is fed into a purpose-designed machine, pressurised and introduced into a high velocity air stream and conveyed through flexible hoses to the spraying nozzle. A finely atomised spray of water is added at the nozzle to hydrate the cement and provide the right mix consistency so that an uninterrupted stream of materials can be projected at high velocity onto the shooting surface where the impact compacts the material. Admixtures can be introduced in powder form into the dry-mix, in liquid form with the added water at the spraying nozzle or as a separate injection at the nozzle. Steel or other fibres can be incorporated in the dry-mix.

In the wet-mix process all constituents of mixture shotcrete, including the water, are prepared using standard concrete mixing equipment. The wet mixture is fed to the delivery equipment, such as a concrete pump, which propels the mixture through the deliveryhose by positive displacement or by compressed air. Additional air is added at the nozzle to increase the nozzle discharge velocity and propel the shotcrete into position where it is compacted by its own momentum.

Shotcrete techniques are varied according to the nature of the work but usually concrete is built up in layers of up to $150 \mathrm{~mm}$ thick. Further layers may be applied to achieve greater thicknesses once the underlying layer has achieved a final set. The surface receiving the new shotcrete layer should be free from deleterious substances. This is normally achieved with the nozzle by jet washing with airwater, starting at the top of the structure and working downwards. Tolerances of \pm 10 millimetres over a 3 metre length are attainable on plain flat surfaces, whilst special provisions are required in respect of more complicated shapes or difficult locations.

Usually, where aesthetics is not a concern, shotcrete is left in its natural gun finish. However, a variety of surface finishes can be achieved with both dry and wet application techiques, from a plain, sack-rubbed finish to a detailed, sculpted finish simulating natural rock.

Shotcrete suitable for most requirements can be produced by either the dry-mix or wet-mix process. Each of the two process is characterized by unique advantages 
and disadvantages which can make one or the other more attractive for a particular application.

Rebound, namely the shotcrete material that does not adhere to the substrate, is associated with both shotcrete application techniques. The rebound greatly influences the economic efficiency and also the environmental impact of the production processes [6]. It can vary from 5 to $10 \%$ by mass of applied materials for wet-process and 15 to $40 \%$ for dry-process.

The dry-technique is very flexible, capable of wide variation in throughput, able to handle virtually all types of cement and a wide range of conventional and lightweight aggregates with aggregate sizes up to $20 \mathrm{~mm}$ [7]. The dry-process allows the application of thin layers and on awkward or intricate structures. High rates of application for tunnel construction slope stabilisation and larger areas are also possible. The newer machines available from many manufacturers today are capable of handling moisture contents of up to $10 \%$ with outputs up to $10 \mathrm{~m}^{3} / \mathrm{h}$. Remotely controlled robotic spraying arms are often used in tunnelling work where they enable the sprayed concrete to be placed in situations that could be hazardous for a nozzleman. They also avoid the need for temporary access in order to place the material at high level.

In the dry process the range of aggregate/cement ratio mixes is limited and is typically from $3.5 / 1$ to $4.0 / 1$ by weight. Because the rebound is mainly aggregate, the placed mix is richer in cement than the batched mixture.

The performance characteristics of dry shotcrete are good density, high strength (typically 40 to $50 \mathrm{MPa}$ at 28 days) and very good bond to a suitable substrate. These intrinsic properties is largely controlled by the skilness of nozzleman who projects the stream of materials onto substrate and also adjusts the amount of water added. The water/cement ratio can only be varied within a limited range, as too little water prevents the mixture compacting into a homogenous mass, while an excess makes it too workable, causing slumping. Incorrect application may result in poor compaction that decreases the strength and durability of the dry shotcrete.

The wet-process uses a higher water/cement ratio than the dry process. However, in this process the water/cement ratio can be accurately controlled and with the use of water reducing plasticisers water/cement ratios below 0.45 can be easily achieved. In the wet-process it is also possible to use air entraining agents to increase the resistance to freeze/thaw cycles.

In the wet-process concrete strength requirements can be specified in a similar manner to conventional concrete although in the wet process high strengths are usually achieved due to the cement rich characteristic. It is usual for wet mix design to use cement contents in the range of $350 \mathrm{~kg}$ to $450 \mathrm{~kg}$ per cubic metre. The resulting cube strengths is normally between $30 \mathrm{MPa}$ and $60 \mathrm{MPa}$ at 28 days.

The wet-process equipment can produce high outputs from $4 \mathrm{~m}^{3} / \mathrm{h}$ to $25 \mathrm{~m}^{3} / \mathrm{h}$, lending itself to tunnel construction or where large structural volumes are required.

Wet-mix shotcrete is generally easier to finish than dry-mix shotcrete because it has a more workable consistency. Excess material is trimmed, sliced, or scraped to grade using a rod or trowel. This gives the shotcrete a natural rod finish sufficient for many remedial applications. Brooming, floating, or troweling the surface can produce other textures. Another approach to finishing is applying a 
thin flash or finish coat using a sanded mixture. Apply the mixture at a plaster-like consistency, then screed, float, or trowel to achieve the required surface texture.

\section{High performance shotcrete}

High performance shotcrete are characterized by significantly enhanced technological properties and improved durability compared to traditional shotcrete based on a mixutre of cement and aggregate. These novel shotcrete materials are obtained through the addition of chemical admixtures, silica fume, fly ash and reinforcement fiber $[3,4,8]$. Following the advantages related to their use in shotcrete mixture are highlighted with particular emphasis on the repair applications.

\subsection{The use of chemical admixtures}

Today, a variety of novel chemical admixtures can be added to shotcrete to improve strength, adhesiveness, cohesiveness, freezing/thawing and abrasion resistence characteristics and to reduce rebound [8-14].

Accellerating admixtures are commonly used in both dry-process and wetprocess. In dry-process their use increases early strength and reduces rebound and dust. In wet-process liquid accellerators, added through a separate line at the nozzle, allow rapid set and early strenght. Historically, at first highly alkaline admixtures such as aqueous sodium silicate $\left(\mathrm{Na}_{2} \mathrm{SiO}_{3}\right.$, "water glass") or powdery sodium aluminate $\left(\mathrm{NaAl}(\mathrm{OH})_{4}\right)$ were used. While they effectively reduce rebound because of an almost instantaneous stiffening effect on concrete, their major disadvantages are a significantly reduction of ultimate strength with values typically in the range $20-50 \%$ compared to plain stocrete (without accelerators) and an unhealthy environment for workers due to handling alkalis. For these reasons, the alkaline accelerators have been replaced by aluminate-based accelerators. These alkali-free accelerators have solved the problem of high toxicity, but still exhibit a disadvantage as their accelerating effect leads to a significantly decreased compressive strength. As a consequence an increased layer thickness is required for shotcrete applications. To avoid this phenomenon of decreased strength, researchers have developed admixtures which reduce rebound not by acceleration, but by increased viscosity [14]. One such admixture which is commercially applied in large quantities contains a blend of polynaphthalene sulfonate (BNS), a common superplasticizer, and polyethylene oxide (PEO), a viscosifier. The combination of these two apparently antagonistic admixtures at a weight ratio of $\sim 8: 1$ (BNS:PEO) results in a very strong synergistic effect which produces a drastic increase in viscosity and a significantly reduction of rebound.

\subsection{Silica fume}

Silica fume is an amorphous silicone dioxide, a by-product of the ferrosilicon industry. Silica fume has been found to provide superior performance for both concrete and shotcrete. The very fine particle of silica fume, approximately one hundred times smaller than that of the cement particle, reacts by a pozzolanic 
reaction with the hydrated lime (Calcium Hydroxide) generated by cement hydration. This results in increased compressive strength, considerable decrease in permeability and improved chemical resistance. Silica fume is typically added at 8 to $10 \%$ by mass of cement. The addition of silica fume in dry or wet shotcrete materials increases the internal cohesion of the mixes and thus allows a high vertical or overhead build-up. The addition of silica fume also decreases the rebound of the material during the application. This is particularly noticeable in wet shotcrete materials where the rebound can be reduced to very small amounts. One of the negative aspects in use of the silica fume is susceptibility of the mixes to plastic shrinkage cracking, but this can be well controlled by a proper curing procedure, mainly in the early curing. The high surface area of the silica fume also requires the use of high range water reducing agents in wet shotcrete.

Silica fume-modified shotcrete mixtures are widely used in bridge retrofits, marine structure repair, and for underground support in tunnels and mines.

\subsection{Fly ash}

Fly ash is a waste by-product from the burning of coal for power generation. Fly ash has been widely used in shotcrete mixtures for many of the same reasons it's used in concrete. It improves the workability and pumpability of wet-mix shotcrete, reduces the heat of hydration and, consequently, the potential for thermal cracking in thick sections, improuves the durability of shotcrete in many aggressive environments, reduces the costs of material production.

For cast-in-place concrete, fly ash is typically added at between $20 \%$ to $50 \%$ by mass of the total cementitious materials. For shotcrete, fly ash is typically added at between 15 to $20 \%$ by mass of the total cementitious materials.

A recent development has introduced wet-mix shotcrete with a high quantity of fly ash ranging from $40 \%$ to $60 \%$ by mass of the total cementitious materials along with water reducers and high dosages of superplasticizers to produce a low water-cement ratio. The resulting shotcrete has good volume stability (low drying shrinkage capacity), good freeze-thaw durability, and very low chloride permeability compared with conventional wetmix, portland-cement shotcrete.

These are desirable characteristics for repair and rehabilitation applications, but further research is needed to assess high-volume fly ash shotcrete performance.

\subsection{Reinforcement fibres}

A major advance in shotcrete technology has been the use of reinforcement fibres. In larger quantities the fibre reinforcement can replace the traditional reinforcing bars or steel mesh reinforcement. In smaller quantities the main function of the fibre is in the reduction or elimination of drying shrinkage cracking.

The introduction of fibres increases the tensile and flexural strengths and crack resistance. The reinforcing effect of the fibres increases with the amount and the modulus of elasticity of the fibre used.

There are three main types of fibres that have been used: steel fibres, alkaline resistant glass fibres and polymeric fibres. 
The steel fibres provide a very effective reinforcement and has been the most widely used in shotcrete mixes to date in both dry and wet shotcrete. They are particularly useful for remedial applications in aggressive chemical or marine environments because steel-fiber-reinforced shotcrete (SFRS) has an outstanding resistance to corrosion. As long as the shotcrete matrix retains its inherent alkalinity and remains uncracked, deterioration of SFRS is unlikely. Corrosion of the discreet steel fibers occurs only to the depth of surface carbonation in the shotcrete. To avoid the corrosion of the fibers onto the surface, a flash coat of plain shotcrete (unreinforced shotcrete) can be applied. Moreover, SFRS has another important advantage: it eliminates the shadowing and voiding problems sometimes encountered in conventional shotcrete repairs in which steel bars are utilized as reinforcement.

Alkaline resistant glass fibre exhibits a high modulus of elasticity and can be easily mixed into mortars in larger quantities than the steel fibre. Also the finish ability of glass fibre reinforced mortar is very good. Alkaline resistant glass fibre is typically used in the wet shotcrete process, but it could be incorporated in the dry process as well. Alkaline resistant glass fibre reinforced shotcrete is used primarily in concrete restoration: ceilings, walls and beams of concrete parking garage structures, bridge structures and in industrial concrete restoration. Polymeric fibres, typically mono-filament polypropylene, have been also used in the dry or wet shotcrete processes. The main limitation of the polypropylene fibre reinforcement is its low modulus of elasticity.

The polypropylene is primarily used to control plastic shrinkage cracking and to a limited degree, drying shrinkage cracking. Its main advantages are relatively low cost and chemical inertness in alkaline mortars and concrete.

\section{Case histories of the shotcrete process in the rehabilitations and repairs of heritage buildings}

\subsection{Rehabilitation of the Vancouver Block Building}

The Vancouver Block Building was built in 1911 and was one of the first high rise buildings constructed in downtown Vancouver, British Columbia, Canada. With 15 floors and a central clock tower, the building has a height of about 65 meters. The building has a steel-framed structure with stucco clad brick masonry walls on the north and south sides and architectural terracotta hollow brick cladding on the east and west sides. This construction belongs to the list of building and structures classified as heritage building by the Canadian law.

In early 1997, during painting work, cracks were discovered in the exterior finishing and in the masonry infill. A detailed investigation of the building envelope revealed that the structural steel columns and beams were affected by an extensive and severe corrosion due to the moisture penetration through the stucco and masonry cladding. Consequently, a retrofit intervention was planned. Figure 1 shows the north and west elevations of the building before the rehabilitation works. 


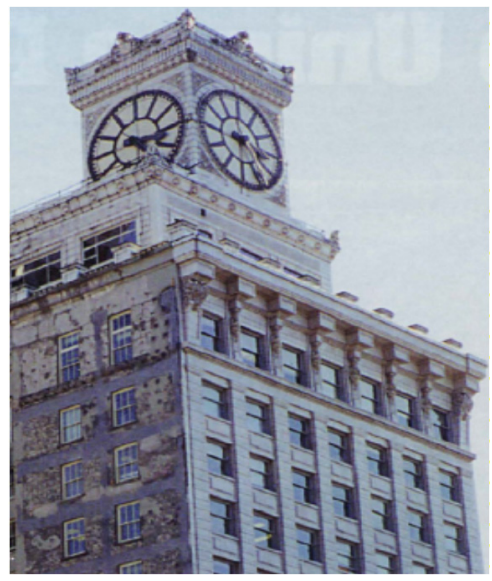

Figure 1: The north and west elevations of the Vancouver Block Building before the rehabilitation works.

The main requirements of the rehabilitation project were to preserve the original impressive appearance of the historic building, to encase and protect the steel-frame structure by the entry of water and to perform all repair work from the outside because the building, which serves as an office building, could not be evacuated during rehabilitation.

In order to satisfy the above-mentioned imperative requirements it was used a shotcrete containing silica fume with a low permeability and high mechanical resistance [15]. Moreover, the facades of building were covered by high scaffolding or, in the areas which were unsuitable for the erection of scaffolding, provided by swing stages (Figure 2). Steel corrosion products were removed by needle scaling and sandblasting. New steel rebar was installed in the previously brick-filled cover to the steel frame and shotcrete was applied to encase the rebar and fill the void. Figure 3 shows the application of shotcrete from a swing stage.

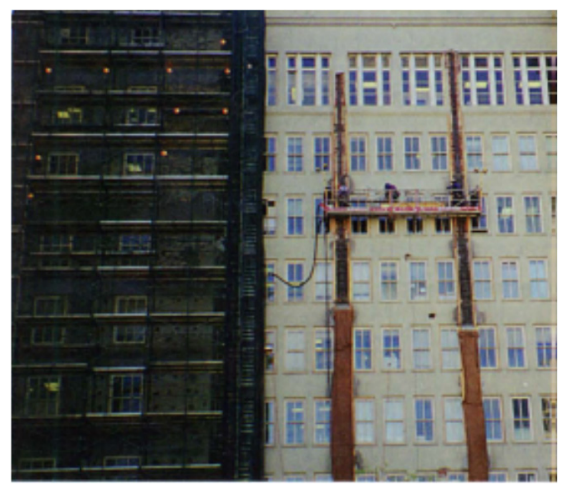

Figure 2: The use of swing stages and scaffolding during the rehabilitation works. 


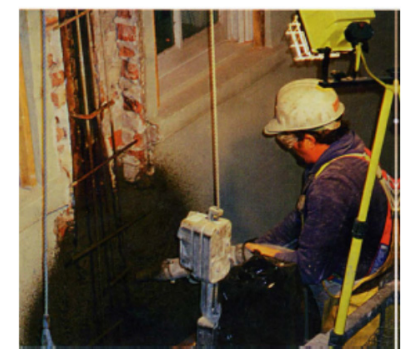

Figure 3: The application of shotcrete from a swing stage.

The south side of the building was rehabilitated using the dry-mix shotcrete process for its inherent advantages over the wet-mix process, such as greater ease of operation in the stop-and-go mode and lighter equipment to move up and down the scaffolding. The repair on the north face involved working over a neighboring property which needed to be protected from contamination by shotcrete rebound and overspray. For this reason the rehabilitation of north side was performed using the wet-mix shotcrete process that produces significantly less dust and rebound compared to the dry-mix process.

The thickness of applied shotcrete varied from 20 to $300 \mathrm{~mm}$. The shotcrete achieved 28-day compressive strengths of between 40 and $50 \mathrm{MPa}$ and values of $4 \%$ boiled absorption and $9 \%$ volume of permeable voids in testing conducted to ASTM C692. The shotcrete surface texture obtained with a final trowel finish and blended well into the texture of the surrounding existing stucco finish.

After finishing the structural repair and the shotcrete work, the building received a new elastomeric paint coating. Figure 4 shows the completed north and west sides of the building after painting. All work was carried out with the structure fully occupied and used as an office building. The use of shotcrete of excellent quality allowed to improve the long term durability of the heritage building and to preserve its original appearance.

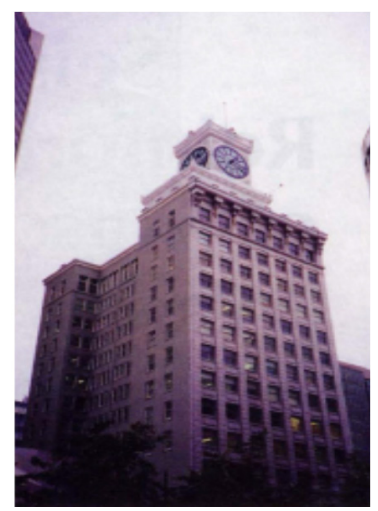

Figure 4: The north and west elevations of the Vancouver Block Building after the rehabilitation works. 


\subsection{The repair of South Side Market House}

The South Side Market House is a historic market located in downtown Pittsburgh, Pennsylvania, United States (Figure 5). It was originally built in 1893 and rebuilt again in 1915 after a fire. The building is listed on the American National Register of Historical Places and has served many different uses over the years. In its earliest days, the Market House held livestock for auction that were kept in pens in the basement. On the front of the building's facade there is a stone bull's head which reminds its original function. Currently, it is used for recreational activities, social events, and meetings.

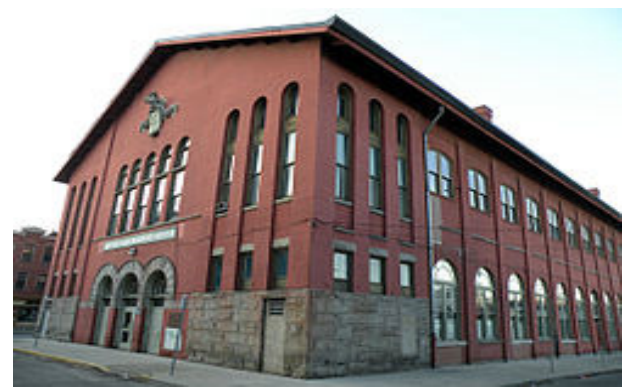

Figure 5: South Side Market House in Pittsburgh, Pennsylvania, United States.

In March 2011 the Market House was closed due to the structural problems in the floor system supported by a series of brick arches that have been seriously deteriorated over time (Figure 6). The repair work was accomplished from the underside without removing the existing floor with the application of a monolithic overlay of dry-shotcrete over the brick arches [16]. Before the shotcrete placement, the brick arches were water-blasted to remove loose mortar and remove dust, dirt, and other particulates from the receiving surface. A galvanized gauge steel mesh was installed and anchored in place with expansion-sleeve J-hook anchor bolts. The use of shotcrete allowed performing the repair work around all obstructions, piping, conduit, and supports (Figure 7).

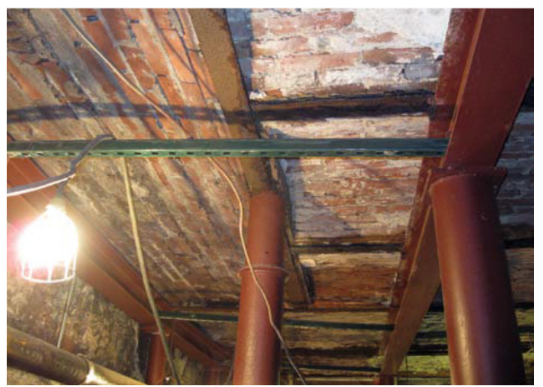

Figure 6: The general condition and configuration of the brick arches. 


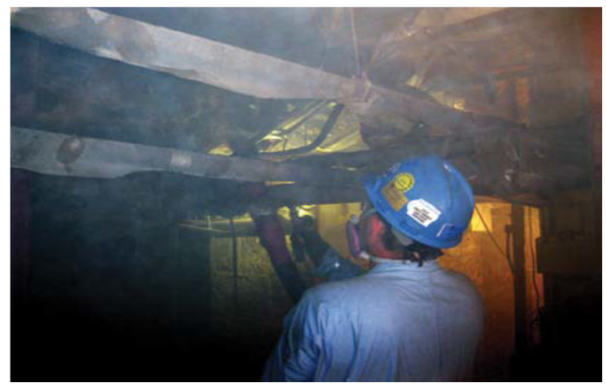

Figure 7: The application of shotcrete in an especially congested area of the basement behind the elevator shaft.

The shotcrete filled in all the deteriorated mortar joints, tightened up and stabilized the floor system support.

The shotcrete was gunned in place quickly and efficiently and provided a very inexpensive yet durable method of repairing the floor system. On June 25, 2012, the South Side Market House was open to the community.

\section{Concluding remarks}

In over 100 years since the shotcrete process was developed, many advancements have been occurred in the equipment, in the dry- and wet techniques required for pneumatically application and in materials technology. These significant developments have derived largely from the requirement of engineers and contractors to improve the quality and durability of shotcrete, increase shotcreting productivity and economy and expand the range of shotcrete applications. Today, shotcrete can be regarded as the most unique and technologically advanced concrete construction method.

High performance shotcrete, including new generations of chemical admixtures, supplementary cementitious materials such as silica fume and fly ash, reinforcement fibres and polymer modifiers, can play a valuable role in repair and rehabilitation projects. The use of these novel shotcrete materials allows to perform economical, effective and durable repair works.

\section{References}

[1] ACI Committee 506, ACI 506R-05: Guide to Shotcrete, American Concrete Institute: Farmington Hills, Michigan, pp. 1-40, 2005.

[2] Warner, J., Understanding shotcrete - The fundamentals. Concrete International, 17(5), pp. 59-64, 1995.

[3] Yoggy, G.D., The History of Shotcrete. Shotcrete Classics, Summer, pp. 26-32, 2005.

[4] Zhang, L., Is Shotcrete sustainable? Shotcrete, 12(4), pp. 20-26, 2010.

[5] Warner, J., History of Shotcrete in Seismic Retrofit in California. Shotcrete, 11(4), pp. 14-17, 2004. 
[6] Pfeuffer, M., Kusterle, W., Rheology and rebound behaviour of dry-mix shotcrete. Cement and Concrete Research, 31, pp. 1619-1625, 2001.

[7] Liu, W.V, Apel, D.B., Bindiganvile, V.S., Thermal properties of lightweight dry-mix shotcrete containing expanded perlite aggregate. Cement \& Concrete Composites, 53, pp. 44-51, 2014.

[8] Zaffaroni, P., Pistolesi, C., Dal Negro, E., Coppola, L., Collepardi, M., High Performance Shotcrete. L'industria italiana del cemento, 7(8), pp. 598-602, 2000

[9] Jolin, M., Beaupre, D., Pigeon, M., Lamontagne, A., Use of set accelerating admixtures in dry-mix shotcrete. Journal of Materials in Civil Engineering, 9(4), pp. 180-184, 1997.

[10] Prudencio Jr, L.R., Accelerating Admixtures for Shotcrete. Cement \& Concrete Composites, 20, pp. 213-219, 1998.

[11] Paglia, C., Wombacher, F., Bohni, H., The influence of alcali-free and alkaline shotcrete accelerators within cement systems. Characterization of the setting behavior. Cement and Concrete Research, 31, pp. 913-918, 2001.

[12] Paglia, C., Wombacher, F., Bohni, H., The influence of alcali-free and alkaline shotcrete accelerators within cement systems. Influence of the temperature on the sulfate attack mechanism and damage. Cement and Concrete Research, 33, pp. 387-395, 2003.

[13] Parc, H.G, Sung, S.K., Park, C.G., Won, J.P., Influence of a $\mathrm{C}_{12} \mathrm{~A}_{7}$ mineralbased accelerator on the strength and durability of shotcrete. Cement and Concrete Research, 38, pp. 379-385, 2008.

[14] Pickelmann, J., Plank, J., A mechanistic study explaining the synergistic viscosity increase obtained from polyethylene oxide (PEO) and $\beta$ naphtalene sulfonate (BNS) in shotcrete. Cement and Concrete Research, 42, pp. 1409-1416, 2012.

[15] Heere, R., Morgan, D.R., Shotcrete Rehabilitation of a Vancouver, BC Historic High Rise Building. Shotcrete Magazine, November, pp. 10-13, 1999.

[16] Sofis, T., The South Side Market House. Shotcrete Magazine, Fall, pp. 3840, 2012. 